statistics can at the present stage be regarded only as an assumption.

The spontaneous transformation of a meson into an ordinary electron and neutrino has been discussed theoretically ${ }^{2}$, and the 'decay period' has been found to be in reasonable accord with observations on the mass absorption anomaly for cosmic rays. We have considered the possibility of a meson being transformed into two heavy particles, a proton and a neutron. The initial energy of the meson must of course exceed about $2 M c^{2} \sim 2 \times 10^{9}$ ev., $M$ being the proton mass, to provide the proton and neutron rest-mass energies. The transformation probability is proportional to $g^{2}$, where $g$ is the usual constant (dimension, electric charge) characterizing the strength of the nuclear field surrounding a neutron or a proton. This probability comes out to be very high, and it seems that the protons and neutrons found in cosmic rays are possibly due to the spontaneous transformation of mesons of very high energies

Bose Research Institute, R. C. Majumdar. Calcutta.

University of Delhi,

\section{S. KOTHARI.} Delhi. Feb. 14.

2 Arley and Heitler, NATERF, 142, 158 (1938). These authors assume the neutrettos to follow Bose statistics.

${ }^{2}$ Euler, H., and Heisenberg, W., Ergeb. exakt. Naturwis8., 17, 27 (1938).

\title{
Physics AND Chemistry
}

\section{Preliminary Report on the Masses of ${ }^{12} \mathrm{C}$ and ${ }^{14} \mathrm{~N}$}

WITH a newly constructed mass-spectrograph of Bainbridge and Jordan type ${ }^{1}$, we measured the mass differences of ${ }^{12} \mathrm{CH}_{4}-{ }^{16} \mathrm{O}$ and of ${ }^{12} \mathrm{CH}_{2}-{ }^{14} \mathrm{~N}$. These ions were produced by electric discharge through a mixture of methane, carbon dioxide and air in a cylindrical discharge tube of the usual type. In addition to these doublets, lines of $\mathrm{NH}_{3}, \mathrm{NH}_{2}, \mathrm{CH}_{3}$, $\mathrm{CH}, \mathrm{C}$ were also simultaneously obtained on the same plate. Photographic plates employed in this work were prepared from the commercial process plates by Schumannization, 10-20 seconds being sufficient for photographing spectral lines on these plates.

By measuring every interval of these lines with ${ }^{1} \mathrm{H}=1 \cdot 008$, a dispersion coefficient at every point on the plate was determined empirically as accurately as we wanted.

Since difference in dispersion coefficient at various parts of the plate was found to be very slight, and moreover no systematic error took place during the measurement, the determination of dispersion coefficient with our method can be quite justified, and the following results were obtained:

$\begin{array}{ccc}\text { Doublet } & \begin{array}{c}\text { Number of } \\ \text { doublets } \\ \text { measured }\end{array} & \text { Difference of mass } \\ { }^{12} \mathrm{CH}_{4}-{ }^{16} \mathrm{O} & 16 & 0.03642 \pm 0.00009 \\ { }^{12} \mathrm{CH}_{2}-{ }^{16} \mathrm{~N} & 38 & 0.01257 \pm 0.00006\end{array}$

From these results and Aston's ${ }^{1} \mathrm{H}=1 \cdot 00812 \pm$ $0.00004^{2}$, isotopic masses of ${ }^{12} \mathrm{C}$ and ${ }^{14} \mathrm{~N}$ can be calculated as follows :

$$
\begin{aligned}
& { }^{12} \mathrm{C}=12 \cdot 00394 \pm 0 \cdot 00018 . \\
& { }^{14} \mathrm{~N}=14 \cdot 00761 \pm 0 \cdot 00021 .
\end{aligned}
$$

A full account will be published elsewhere.

$$
\begin{aligned}
& \text { T. Asada. } \\
& \text { T. OKuda. } \\
& \text { K. Ogata. } \\
& \text { S. Yoshimoto. }
\end{aligned}
$$

Department of Physics,

Osaka Imperiạl University, Osaka.

March 23.

1 Bainbridge and Jordan, Phys. Rev., 50, 282 (1936).

2 Aston, Proc. Roy. Soc., A, 163, 391 (1937).

\section{Discrepancies in the Isotopic Weight of ${ }^{12} \mathrm{C}$}

OF some forty isotopic weights so far determined by the doublet method, more than half depend on that of ${ }^{12} \mathrm{C}$ as a substandard. As chairman of the International Committee on Atoms, I am anxious that some agreement should be reached on this isotopic weight to enable a satisfactory table to be adopted. Ill-health has prevented me making any further measurements for the past year, but Mattauch has recently published results ${ }^{1}$ indicating that my value $12.00355 \pm 0 \cdot 00015$ is too low. He gives as his own $12 \cdot 003876 \pm 0 \cdot 000032$, closely agreeing with Bainbridge and Jordan's latest value, $12 \cdot 00398 \pm$ $0 \cdot 00009$. Much as I regret being compelled to criticize the results of other workers, I feel it may be well to explain some of the reasons which prevent me accepting the high value with entire confidence.

My first criticism concerns the accuracy claimed. My own figure corresponds to an uncertainty of position of a line on the photographic plate of $0.0075 \mathrm{~mm}$., Bainbridge's to $0.0045 \mathrm{~mm}$.; Mattauch's, owing to the much smaller dispersion of his apparatus, to $0.0003 \mathrm{~mm}$., which seems very small for photometric measurements. My second and more important criticism is the possibility of some systematic error in the instruments. The fundamental discrepancy in the doublet $\mathrm{O}-\mathrm{CH}_{4}$ could be explained by supposing that my apparatus gives the mass of the molecule too low relative to that of the atom, or that the other types give it too high. What evidence is there for either of these possibilities? Suspicious of the first, I checked the mass of ${ }^{12} \mathrm{C}$ by as many different methods as possible ${ }^{2}$. One, the doublet $\mathrm{CO}-\mathrm{C}_{2} \mathrm{H}_{4}$, only used molecules and others only used atoms; all gave results consistent with my low value, which was further supported by more measurements of the doublet ${ }^{40} \mathrm{~A}-\mathrm{C}_{3} \mathrm{H}_{4}{ }^{3}$ and by work on ${ }^{48} \mathrm{Ti}{ }^{4}$.

The three doublets $\mathrm{CO}-{ }^{14} \mathrm{~N}_{2}, \mathrm{C}-{ }^{10} \mathrm{BH}_{2}$ and ${ }^{20} \mathrm{Ne}-\mathrm{CD}_{4}$ quoted by Mattauch to check his high value are neutral in their evidence, for it so happens that if my values for all the atoms concerned are put in, the agreements are equally good.

To use a loose optical analogy, Mattauch and Bainbridge's double focusing is related to my single focusing as a lens to a pin-hole. The lens gives greater sharpness, higher resolution and in most cases higher accuracy, but it may on the other hand 